\title{
THE EFFECTS OF DEEP BALCONY OF DIFFERENT BUILDING HEIGHTS ON INDOOR LIGHTING AND THERMO- ENVIRONMENT
}

\author{
LIU, K. S. ${ }^{*}$ - CHEN, C. C. \\ Department of Interior Design, Tung Fang Design Institute \\ No.110, Dongfang Rd., Hunei Dist., Kaohsiung City 82941, Taiwan (R.O.C.) \\ *Corresponding author \\ e-mail: kliu1219@yahoo.com.tw; tel: +886-9-287-51652; fax:+886-7-693-9657 \\ (Received 12 $2^{\text {th }}$ Aug 2016; accepted $15^{\text {th }}$ Nov 2016)
}

\begin{abstract}
The plan for the "Kaohsiung area building" was based on the "different building height depth research on indoor warm sun sets and lighting environmental benefits of Planning" design evaluation. Kaohsiung houses' existing buildingswere studied for building information model of "building energy simulation" so as to simulate and evaluate the effectiveness of deep shade type balcony design. The purpose of studying both Houses of different types of buildings in Kaohsiung is to design energy-efficient building exterior balconies with improved planning and designsso as to improve simulation predictions and improve measures and deliberations.It is also expected to develop design principles of renovations, including the focus on the consolidation and transformation of energy-saving design details of the housing on the practical application of the analysis withcollocation and verified by simulation.The results of the imported ECO-efficiency model (EEM) was used to assess its life-cycle costs and benefits(LCCE) and the research results can providea different building height depth research on indoor warm sun sets and the environmental benefits of daylighting toward the reference design criteria of sustainable building renovation.
\end{abstract}

Keywords: deep shade type balcony,fenestration rate,building high-rise,building energy simulation,building Information Model (BIM), ECO-Efficiency model

\section{Introduction}

According to the statistical data of Kaohsiung Department of Building Affairs: currently, the proportions of "newly built buildings" and "existing buildings" are 7.2\% and $92.8 \%$ respectively (Department of Building Affairs, Kaohsiung City Government, 2014). Among them, the proportion of "residential buildings" is $60.8 \%$, which is the highest. The Kaohsiung City Kaohsiung Lohas Design Measurestipulates relevant provisions on deep balconies. The design of overhanging eave, sunshade, or balcony etc. can bring cool shelter, highlighting the characteristics of climatic environment in Kaohsiung City. A building which sets deep balcony in response to the local sun light exposure should conform to the following circumstances and at the same time may be exempted from calculating into building area or floor area.

The balcony shall be set outside fifteen degrees of the left and right sidesto the north of a building respectively.If the exterior central line extruded from the building or the central line of substituted column of the building exceedthe three-meter limit, the outer edge thereof shall be deducted three meters respectively from the central line, and based on which the maximum horizontal projected area of floor area will be calculated. The balcony of a building below five floors shall be set at the sides of the site facing road, site interior pathway, private pathway or existing roadway.

A balcony with its width within three meters is excluded from the floor area.The sum of the area of the balcony on each floor shall not exceed one fourth of the floor area.If 
the sum of the area is less than twenty square meters, another balcony of twenty square meters shall be built.

For the vertical plane of balcony on each floor, the opening rate from the legal handrail height to the floorboard of the upper floor shall be above one second of the balcony area and the green area of each balcony shall be more than one third.The depth of soil coverage within the green scope of balcony shall be more than 15 centimeters, and there shall be no column in the balcony.

For the living room part of deep balcony set according to this study, the area of each section shall not be less than ten square meters and the depth shall not be less than three meters.

This research carries out reconstruction simulation estimation through the control of different building heights, different depths of deep shade type balconies and different window opening rates (Suh et al., 2014; Yin et al., 2010). Moreover, simulation estimations were conducted based on the "ECO-Efficiency Model" (EEM) (Xu et al., 2014, Volk et al., 2014). The research resultsserve as the reference for Taiwan sustainable green building reconstruction design criterion and became the reference basis of "Building Envelope Energy Saving Reconstruction Design Technical Specification" in future development of "Kaohsiung Lohas".

This research selected one representative case and usedthe Autodesk Ecotect software to conduct 3D modeling and simulation. The simulation contents include: deep shade type balcony depth, area size of window opening part, evaluation of energy consumption of sunshine effect, and in consideration of the effect of indoor lighting and thermo-environment caused by different variable factors. The target of the case study is located at No. 22, Ziqiang 1 Road, Qianjin District, Kaohsiung City. The building structure is RC building. the building has twenty-two floors and is about 66 meters high and the floorboard area of each floor is about $255 \mathrm{~m}^{2}$ (Figures 1 and 2).
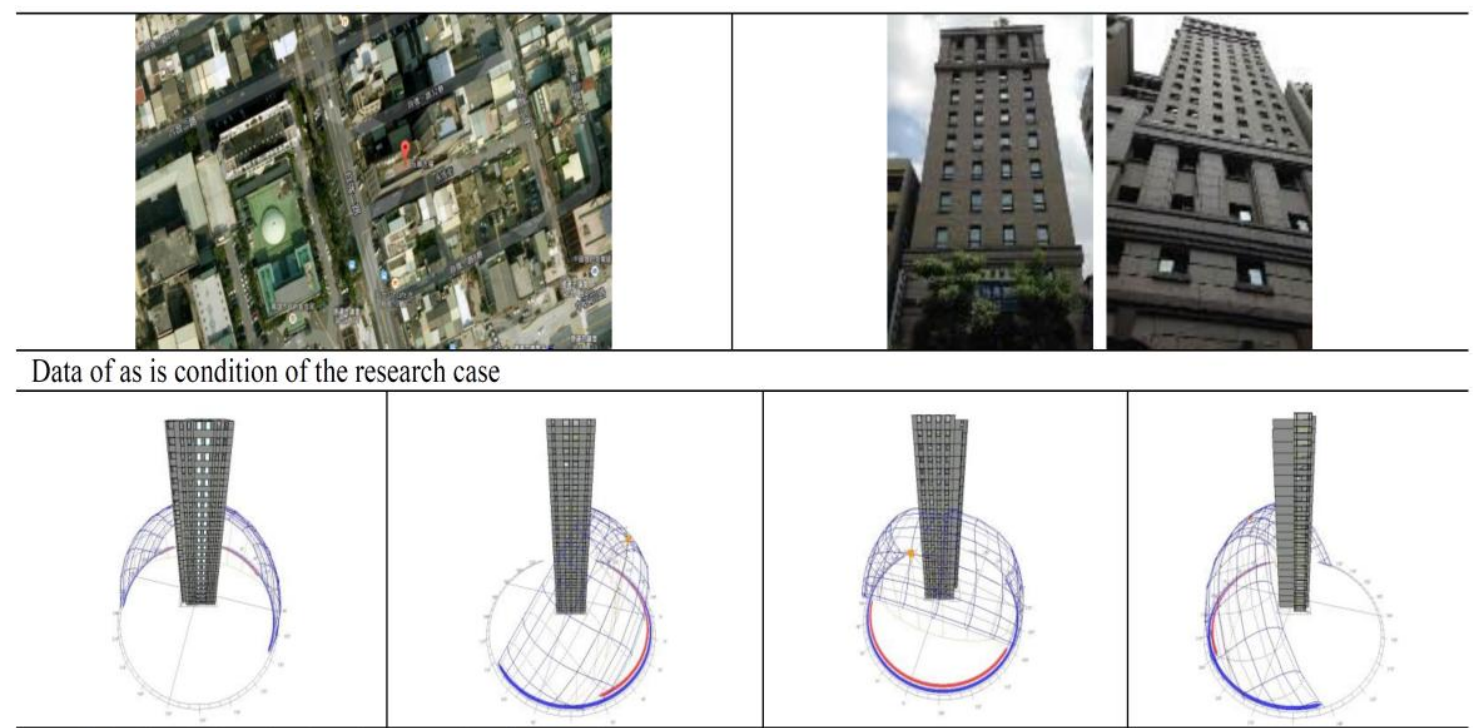

Sunlight simulation simulated 3D graphical expression

Figure 1. Residential Case Indoor Lighting and Thermo-Environment Simulation Evaluation 


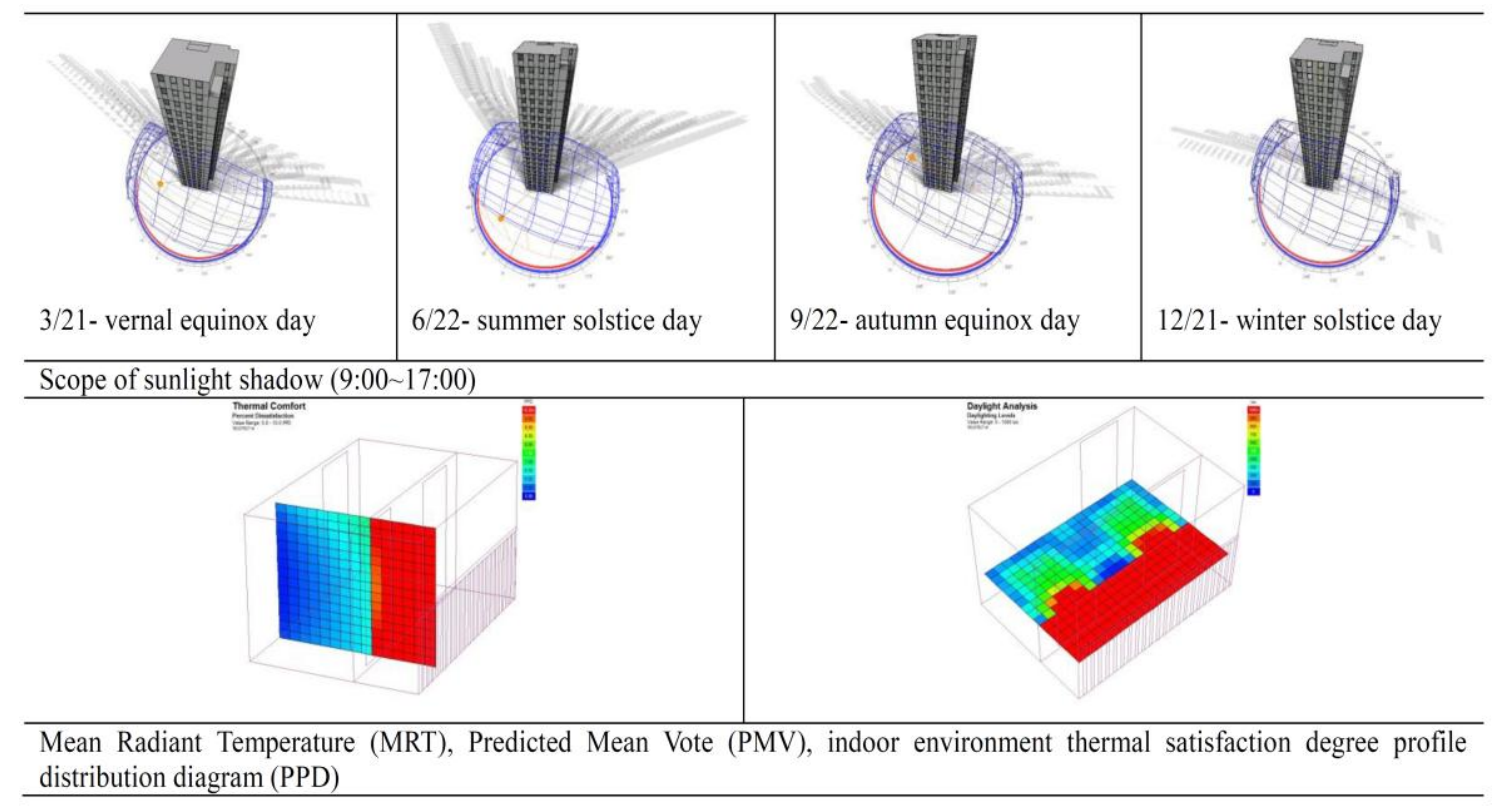

Figure 2. Thermo-Environment Simulation Evaluation

\section{Methodology}

This building sets the direction of facing north, according to different floors $(7 \mathrm{~F}, 16 \mathrm{~F}$, $22 \mathrm{~F})$, different shade depths $(1.5 \mathrm{~m}, 2 \mathrm{~m}, 2.5 \mathrm{~m}, 3 \mathrm{~m})$ and different window opening rates $(50 \%, 75 \%, 100 \%)$.We studied the indoor air conditioner energy consumption, thermoenvironment MRT, PPD, PMV (Fanger, 1970; Fanger, 1972; ISO, 2005) and indoor lighting environment etc. (Tsuzuki índ Iwata,2002; Berglund, 1998) and make comparisonsacross the five simulation results. If taking 1.5 meters as is depth of the balcony as the simulated EUI value as the $100 \%$ reference value, when the deep shade of a balcony increases to 2 meters, 2.5 meters and 3 meters, we have compared four shade-type balcony models of different depths and analyzed the energy saving and indoor lighting improvement effectsof their air conditioners. The setting values of simulation parameters are as shown in Table 1.

Table 1.Thermal Conductivity and Property of Residential Case Materials

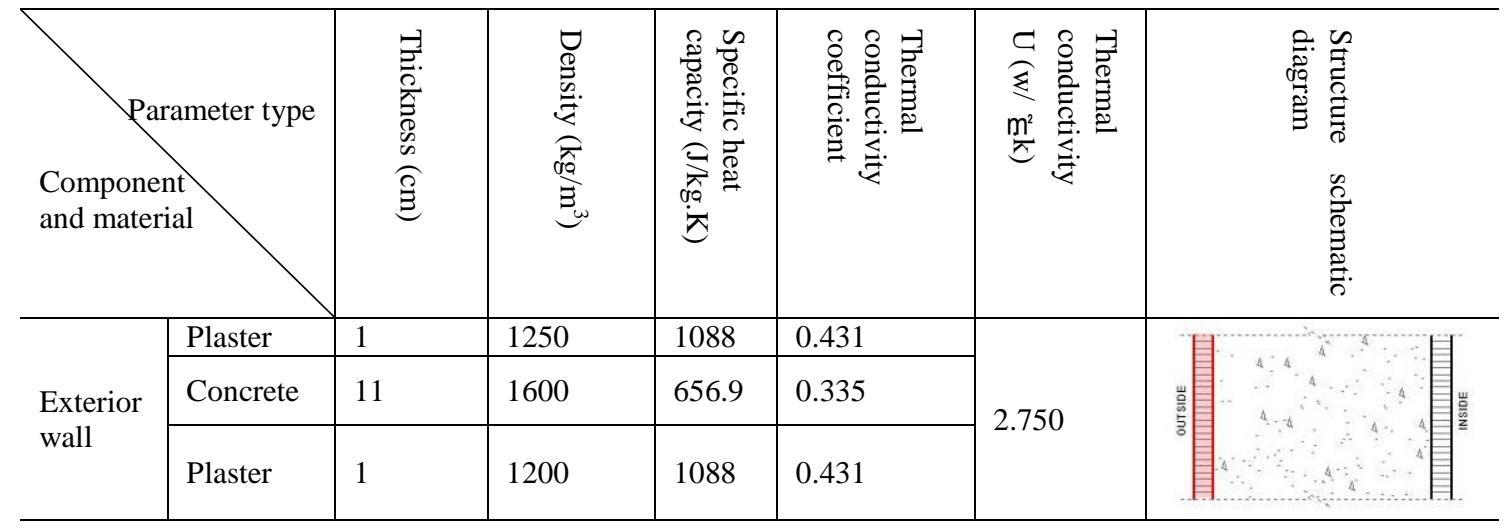




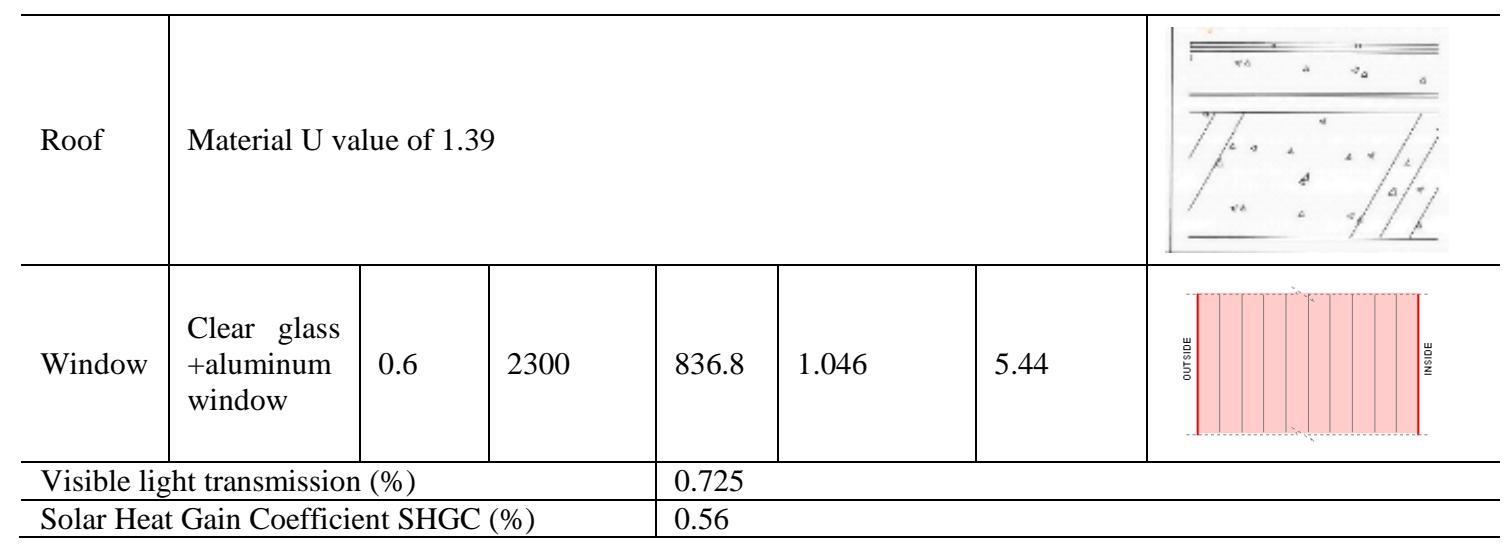

The steps of simulation flow chart are as follows (Table 2):

1. Set the climatic data of Kaohsiung District according to the model site.

2. Review the average time distribution of sunlight radiation per year in Kaohsiung District (the simulation indicates that it is the highest at 16:00 of June).

3. Conduct model construction according to the as is condition of the current case, the current balcony depth of the case sets as 1.5 meters.

4. Conduct all-year air conditioner energy consumption simulation according to the setting of climatic data of Kaohsiung District.

5. Simulate indoor black ball temperature (set the temperature at $23^{\circ} \mathrm{C} \sim 28^{\circ} \mathrm{C}$ )

6. Simulate PMV (set as 0-1)

7. Simulate PPD (set as 5 90)

8. Simulate indoor daylighting illumination (set at 0 1000Lux)

Complete one group of simulation case.

Table 2. Flow Chart of Simulation Steps

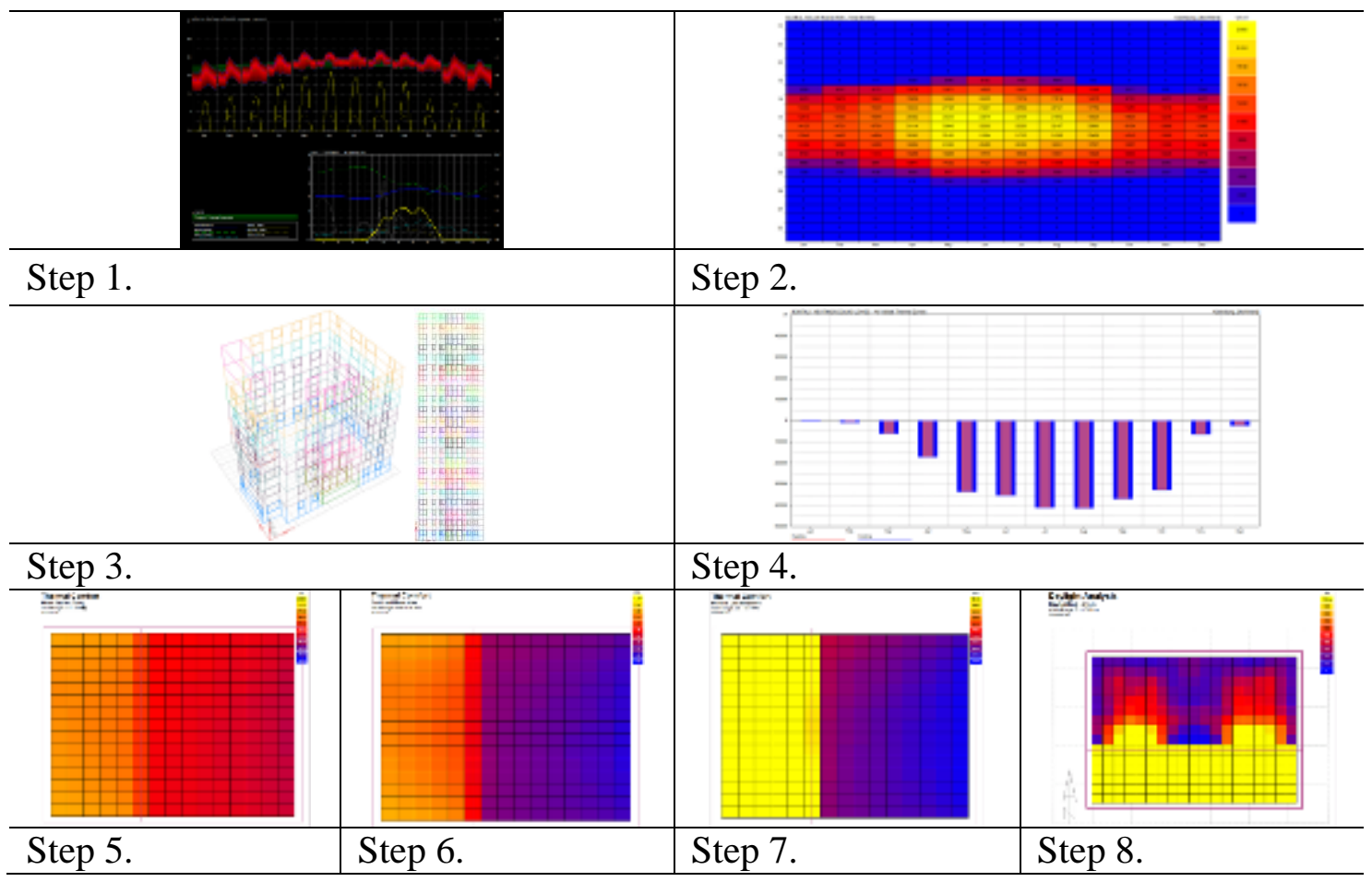




\section{Results}

\section{Analysis of air conditioners' energy consumption simulation}

This study established the model according to the actual as is condition of the case, and takes the current balcony depth 1.5 meters as the reference value so as to simulate the air conditioner energy consumption EUI value (see Table 3) of different balcony depths $(1.5 \mathrm{~m}, 2 \mathrm{~m}, 2.5 \mathrm{~m}$ and $3 \mathrm{~m})$, different floors $(7 \mathrm{~F}, 16 \mathrm{~F}, 22 \mathrm{~F})$ and different window opening rate of the opening part (as is condition, 50\%, 75\%, 100\%) under the same external condition.

Table 3. Resultsof Air Conditioner Energy Consumption EUI Simulation

\begin{tabular}{|c|c|c|c|c|}
\hline Balcony depth & $1.5 \mathrm{M}$ & $2 M$ & $2.5 \mathrm{M}$ & $3 M$ \\
\hline \multicolumn{5}{|c|}{ As is condition } \\
\hline $7 F$ & 115,985 & 104,288 & 93,122 & 82,264 \\
\hline $16 \mathrm{~F}$ & 115,956 & 97,846 & 87,341 & 82,279 \\
\hline $22 F$ & 124,131 & 97,983 & 87,525 & 87,496 \\
\hline \multicolumn{5}{|c|}{ Window opening rate $50 \%$} \\
\hline $7 F$ & 116,013 & 101,943 & 91,014 & 82,131 \\
\hline $16 \mathrm{~F}$ & 116,032 & 101,960 & 91,030 & 82,145 \\
\hline $22 \mathrm{~F}$ & 124,377 & 108,948 & 97,146 & 87,515 \\
\hline \multicolumn{5}{|c|}{ Window opening rate $75 \%$} \\
\hline $7 F$ & 147,164 & 129,430 & 114,415 & 103,365 \\
\hline $16 \mathrm{~F}$ & 147,182 & 129,447 & 114,430 & 103,378 \\
\hline $22 \mathrm{~F}$ & 147,902 & 129,570 & 114,582 & 103,530 \\
\hline \multicolumn{5}{|c|}{ Window opening rate $100 \%$} \\
\hline $7 F$ & 172,440 & 149,995 & 132,900 & 120,078 \\
\hline $16 \mathrm{~F}$ & 172,458 & 150,011 & 133,095 & 120,091 \\
\hline $22 F$ & 173,679 & 151,016 & 134,021 & 120,834 \\
\hline
\end{tabular}

According to different depths under the same climatic condition, the simulated indoor air conditioner energy consumption EUI value obviously indicated that the deeper the shade depth, it can effectively reduce the indoor thermal loading so as to reduce the usage of indoor air conditioner and achieve the effect of $\mathrm{CO}_{2}$ emission reduction and energy saving.

Analysis of results of $50 \%$ window opening rate: it can save approximately $12 \% \sim 30 \%$ of the air conditioners' electricity consumption at most.

Analysis of results of $75 \%$ window opening rate: it can save approximately $12 \% \sim 30 \%$ of the air conditioners' electricity consumption at most.

Analysis of results of $100 \%$ window opening rate: it can save approximately $13 \% \sim 31 \%$ of the air conditioners'electricity consumption at most.

Under the same balcony depth and window opening rate, the impact of floor height of low and medium floors on the difference of air conditioner energy consumption is not great, except that the air conditioner energy consumption on top floor in high floor case will rise slightly. By comparison, the window opening rate has greater impact on the indoor air conditioner energy consumption than the shade depth.

Under the same floor height and each window opening rate (as is condition, 50\%, $75 \%$, and $100 \%$ ), the depth of deep shade type balcony indeed can affectthe air conditioners' energy consumption. Since the increase of the window opening rate will 
increase the indoor air conditioner loading, if collocated with deep shade type balcony, it can reduce the impact on indoor air conditioners' energy consumption when increasing the window opening rate.

\section{Thermo-Environment Simulation}

This research also aims at different floors and window opening rates at the same time.We studied the impact of deep shade type balconies on the indoor thermoenvironment through simulation comparison and the simulation data include indoor radiation heat, PMV and PPD. The result indicated that: under the condition of same floor, the deeper the balcony depth, the less radiation heat will go indoors. Under the condition of same shade depth, there is no obvious difference in the performance among the low and medium floors, since such simulated high floor is the top floor, the performance effect of deep shade type balconies on high floor is higher than that on low and medium floors.

\section{Indoor Lighting Simulation}

The main impacting variable factors of the indoor lighting environment are the depth of deep shade type balconies and the window opening rates.Moreover, there is no obvious difference among the performance of floor height. The deeper the balcony depth, the less natural light will go indoors and this can reduce the indoor air conditioners' energy consumption relatively. The higher the window opening rate, it can increase the indoor illumination more directly, which increases the indoor air conditioner energy consumption.

\section{Discussion}

According to the statistics of GBI, which is mainly based on the frigid climate countries in Europe and America, the energy consumption of a greenhouse system is switched into energy consumption of cool house and thermal insulation.Among them, the proportion of energy consumption of doors and windows are as high as more than $23 \%$. Given this, if the energy consumption in the part of windows can be reduced effectively (Shao et al.,2014), it will contribute to the effect of a certain degree in the control of building energy consumption(Tzeng et al.,2013).

According to the conclusion of the early research(Liu et al., 2014), we can conclude that:

1. The deep shade type balcony can improve the benefit and effect in indoor energysaving and can reduce almost $12.72 \%$ of indoor air conditioners' electricity consumption.

2. The reconstruction of collocated materials of a building envelope and the increasing use of thermal insulation building materials can improve the energy saving benefit, especially then the depth of deep shade type balcony is $3 \mathrm{~m}$.After improving the collocated envelope construction materials, up to $40.16 \%$ of air conditioner energy consumption can be saved at most.

3. The deeper the depth of the deep shade type balcony, the better the energy saving effect will be; the higher the deep shade floor, the better the energy saving effect will be. 


\section{Conclusion}

1. For a window opening rate of $50 \%$, it is suggested to adopt $2.5 \mathrm{~m}$ deep shade type balcony. When sacrificing partial natural lighting, it can save about $21-22 \%$ of the electricity consumption.

2. For a window opening rate of $75 \%$, it is suggested to adopt $3 \mathrm{~m}$ deep shade type balcony. Without impacting the indoor natural lighting, it can save about $29-30 \%$ of the electricity consumption.

3. For a window opening rate of $100 \%$, it is suggested to adopt $3 \mathrm{~m}$ deep shade type balcony. Without impacting the indoor natural lighting, it can save about $31 \%$ of the electricity consumption.

\section{REFERENCE}

[1] Berglund, L. G. (1998). Comfort and humidity. ASHRAE journal, 40(8), 35.

[2] Fanger, P. O. (1972): Thermal comfort. - McGraw-Hill, Atlanta.

[3] Fanger, P. O. (1970). Thermal comfort. Analysis and applications in environmental engineering. Thermal comfort. Analysis and applications in environmental engineering.

[4] International Organization for Standardization (2005). Ergonomics of the Thermal Environment: Analytical Determination and Interpretation of Thermal Comfort Using Calculation of the PMV and PPD Indices and Local Thermal Comfort Criteria. International Organization for Standardization.

[5] Department of Building Affairs Kaohsiung City Government (2014). Kaohsiung city government Annual Report.

[6] Liu, K.S., Shih, Y.L., Tzeng, C.T., Chen, C.C.(2014): Research on energy-saving design transformation on the external shell of existing buildings - the example of Kaohsiung City townhouses. - Journal of Environmental Protection and Ecology 15(3A):1303-1314.

[7] Shao, L., Chen, G. Q., Chen, Z. M., Guo, S., Han, M. Y., Zhang, B., Ahmad, B. (2014): Systems accounting for energy consumption and carbon emission by building. Communications in Nonlinear Science and Numerical Simulation 19(6): 1859-1873.

[8] Suh, S., Tomar, S., Leighton, M., Kneifel, J. (2014): Environmental performance of green building code and certification systems. - Environmental science \& technology 48(5):2551-2560.

[9] Tsuzuki, K., Iwata, T. (2002): Thermal comfort and thermoregulation for elderly people taking light exercise, Indoor Air 2002. - Proceedings of the 9th International Conference on Indoor Air Quality and Climate, Monterey, California, June 30-July 5, Vol. 4: 647-652

[10] Tzeng, C.T., Du, W.D., Zhand, W.Z., Su, D.Y.(2013): Study on the installation of building shading panels and the usage of daylight. - Air-cond Energy Technol. 84:36-45.

[11] Volk, R., Stengel, J., Schultmann, F. (2014): Building Information Modeling (BIM) for existing buildings-Literature review and future needs. - Automation in construction 38: 109-127.

[12] Xu, H., Feng, J., Li, S. (2014): Users-orientated evaluation of building information model in the Chinese construction industry. - Automation in Construction 39:32-46.

[13] Yin, H., Chong, Z., Ahmed, A. (2010): Building performance analysis based on modelling and simulation. - In: Proceedings of the International Conference on Computing In Civil and Building Engineering. Nottingham University Press. 